\title{
Field-Weakening Control for Torque and Efficiency Optimization of a Four-Switch Three-Phase Inverter-Fed Induction Motor Drive
}

\author{
Ufot Ufot Ekong*a) Member, Mamiko Inamori* Member \\ Masayuki Morimoto* Fellow
}

(Manuscript received May 16, 2018, revised Aug. 17, 2018)

\begin{abstract}
This paper proposes a field-weakening control strategy to optimize the torque production and motor efficiency of a four-switch three-phase inverter-fed induction motor drive in the high-speed region. A method to control the torque component current $\left(I_{q}\right)$ and the flux component current $\left(I_{d}\right)$ of the field-weakening region is proposed. The feasibility of the proposed control strategy is verified through a simulation and validated experimentally. The results show that the speed-torque characteristics and the motor efficiency are improved in the high-speed region.
\end{abstract}

Keywords: fault tolerant control, vector control, flux weakening control

\section{Introduction}

Due to advances in power electronics, the use of inverterfed induction motor drives has increased in various industries, from consumer goods to industrial applications. In the last two decades, Four-Switch Three-Phase Inverter (FSTPI) has gained a lot of attention for its ability to be applied as a fault tolerant control or an emergency strategy for the conventional 3-phase inverter ${ }^{(1)-(19)}$. FSTPI is also known as twophase inverter, four-switch inverter and two-leg inverter because of its structure as shown in Fig. 1. Some reported works show that an FSTPI has also been applied to Switched Reluctance Motor (SRM), Interior Permanent Magnet Synchronous Motor (IPMSM), Brushless DC Motor (BLDC), and Permanent Magnet Synchronous Motor (PMSM) ${ }^{(1)-(5)}$. Compared to all these different types of motor, an induction motor is more widely used in various industries because of its ruggedness, cost and reliability.

Reported works on FSTPI drive proposed methods to create Pulse Width Modulation (PWM) signals using various modulation techniques like Space Vector PWM and sinusoidal PWM ${ }^{(6)-(8)}$. Other works proposed methods to correct current and torque ripples caused by the voltage unbalance in the capacitors ${ }^{(9)(10)}$. The voltage unbalance compensation has also been investigated using different control strategies both scalar and vector control methods ${ }^{(11)-(14)}$. Unfortunately, most of the reported works focused on the low-speed region or no load condition.

The most challenging feature of an FSTPI drive is that its voltage utilization factor reduces by approximately $50 \%$ compared to the conventional 3-phase inverter drive ${ }^{(15)(16)}$. The authors earlier proposed a direct transformation matrix for FSTPI, to calculate voltage reference signals from dq axis to a two phase voltage signal $\left(V_{A}{ }^{*}, V_{B}{ }^{*}\right)$ to facilitate the

a) Correspondence to: Ufot Ufot Ekong. E-mail: 6ltad001@mail. u-tokai.ac.jp

* Tokai University

4-1-1, Kitakaname, Hiratsuka, Kanagawa 259-1292, Japan

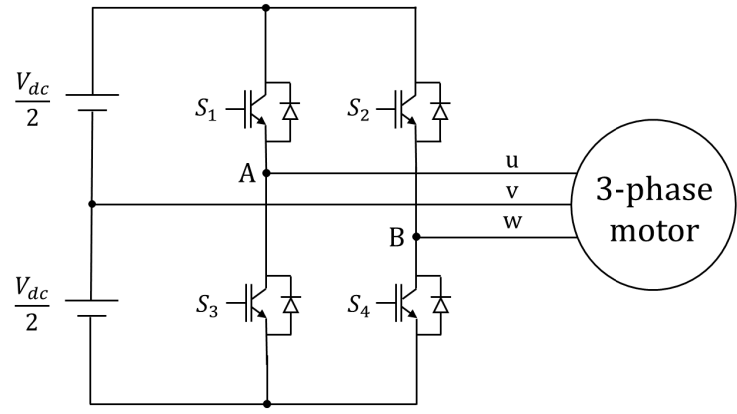

Fig. 1. Structure of Four Switch Three Phase Inverter

generation of sinusoidal PWM signals ${ }^{(17)(18)}$. This transformation matrix enables easy implementation irrespective of the affected phase of the inverter, when an FSTPI is used as an emergency strategy ${ }^{(17)(18)}$. They further reported that the maximum torque attainable speed and motor efficiency in the high-speed region reduces by approximately $50 \%{ }^{(19)}$. In order to apply FSTPI to high performance drives like traction and spindle drives a method to increase the maximum attainable torque and motor efficiency in the high-speed region is required.

In the conventional 3-phase inverter drive, a common method to achieve high speed, torque and motor efficiency over a wide operating range, is to apply a field-weakening control. Field-weakening control methods for the conventional 3-phase inverter drives have been studied widely and can be classified into three categories ${ }^{(20)-(26)}$. (i) Adjustment of the motor flux in inverse proportion to speed. (ii) Feed forward control based on simplified motor parameters. (iii) Closed loop control of the stator voltage for full utilization of the maximum inverter voltage.

The first approach has been reported to improve the speedtorque characteristics but not to its maximum for the available current and utilization of the DC-link voltage ${ }^{(20)(21)}$. The second and third approach are dependent on the fact that the maximum current and DC-link voltage can be fully utilized, 
thus, increasing the maximum attainable torque ${ }^{(22)-(25)}$. However, the second and third approach have been reported to have bad response characteristics ${ }^{(26)}$.

In an FSTPI drive, since the DC-link voltage cannot be fully utilized, the second and third approach are inapplicable or difficult to implement. Therefore, in this research, the first approach is considered and some changes are made in its control strategy to make it applicable to an FSTPI drive. The authors earlier reported on experimental results of an FSTPI drive in the high-speed region by proposing a flux weakening strategy to improve its characteristics ${ }^{(27)}$. However, this strategy did not fully optimize the characteristics of an FSTPI drive in the high-speed region because the current was not adequately controlled and limited.

Hence, the objective of this paper is to investigate the possibility that a field-weakening control can be achieved in an FSTPI fed AC motor drive, by proposing a current control strategy to optimize the performance characteristics of the drive in the high-speed (field-weakening) region using vector control method.

\section{Indirect Vector Control}

Vector control is a popular and commonly adopted control strategy for inverter-fed motor drives because of its simplicity in implementation and dynamic control of speed and torque.

The authors in their earlier works used the indirect vector control method and proposed a method to transform the output voltage reference signals of vector control $V_{d}{ }^{*}, V_{q}{ }^{*}$ to a two phase voltage reference $V_{A}{ }^{*}$ and $V_{B}{ }^{*}$ as shown in Fig. $2^{(17)(18)}$. These voltage references are used to generate PWM signals that drive the inverter. The earlier proposed transformation matrix is shown in equation (1) and equation (2).

$$
\begin{aligned}
{\left[\begin{array}{l}
V_{A}^{*} \\
V_{B}^{*}
\end{array}\right] } & =\sqrt{\frac{2}{3}}\left[\begin{array}{cc}
\cos \theta & -\sin \theta \\
\cos \left(\theta+\frac{\pi}{3}\right) & \sin \left(\theta-\frac{2}{3} \pi\right)
\end{array}\right]\left[\begin{array}{l}
V_{d}^{*} \\
V_{q}^{*}
\end{array}\right] \ldots \ldots \\
V_{A}^{*} & =\sqrt{2} V \cos \omega t \\
V_{B}^{*} & =\sqrt{2} V \cos \left(\omega t+\frac{\pi}{3}\right)^{\cdots \ldots \ldots \ldots \ldots \ldots \ldots}
\end{aligned}
$$

In indirect vector control, the stator current of the motor is decomposed into flux component (d-axis current) $I_{d}$ and torque component (q-axis current) $I_{q}$. These components are then decoupled and controlled individually. The flux component reference $I_{d}{ }^{*}$ is kept constant in the entire speed region. This enables fast response characteristics of the drive especially in the low-speed region, but reduces the stability, torque production and motor efficiency in the high-speed region.

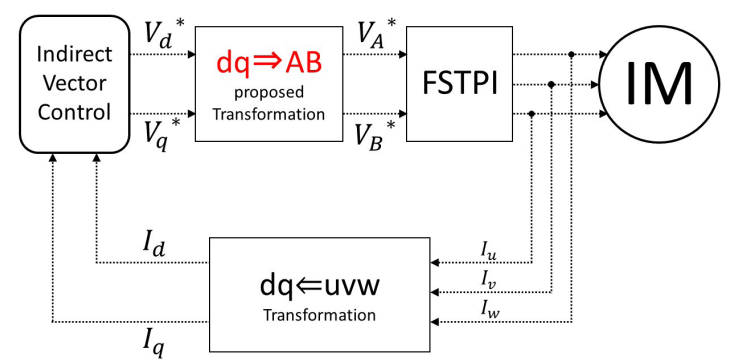

Fig. 2. Indirect Vector Control Method for FSTPI

\section{Operation Constraints in Field-Weakening Region}

In this section, the operation constraints and fieldweakening characteristics of both the Four-Switch ThreePhase Inverter (FSTPI) and 3-phase inverter drive are discussed.

3.1 Voltage and Current Limit In the high-speed region, the performance of an induction motor drive is limited by the voltage utilization factor and current ratings of both the motor and the inverter. However, the voltage utilization factor of the FSTPI drive compared to the 3-phase inverter drive reduces by approximately $50 \%$ as shown in Fig. $3^{(15)(16)}$.

The maximum voltage $V_{\text {smax }}$ that the inverter can apply to the induction motor is determined by the DC-link voltage and the Pulse Width Modulation (PWM) strategy that is adopted. In this paper, the triangular Sine wave PWM is adopted, therefore $V_{\text {smax }}$ is limited to $\mathrm{Vdc} / 2^{(28)}$.

The voltage references in the dq axis $\left(V_{d}{ }^{*}, V_{q}{ }^{*}\right)$ must satisfy the constraints of the voltage limit boundary as shown in equation (3).

$$
V_{\text {smax }} \geq \sqrt{V_{d}^{* 2}+V_{q}^{* 2}}
$$

The motor current is limited to the maximum stator current $I_{\text {smax }}$ which is determined by the thermal rating of the induction motor or the current rating of the inverter. The decoupled current references $I_{d}{ }^{*}$ and $I_{q}{ }^{*}$ must satisfy $I_{\text {smax }}$ as shown in equation (4).

$$
I_{\text {smax }} \geq \sqrt{I_{d}^{* 2}+I_{q}^{* 2}}
$$

As shown in Fig. 4(a), the reference currents $\left(I_{d}{ }^{*}, I_{q}{ }^{*}\right)$ must be limited to the current limit circle in order to maintain current control. The maximum stator current $I_{\text {smax }}$ can be increased depending on the inverter current ratings as shown in Fig. 4(b). The current limit is often $150 \%$ of the rated current

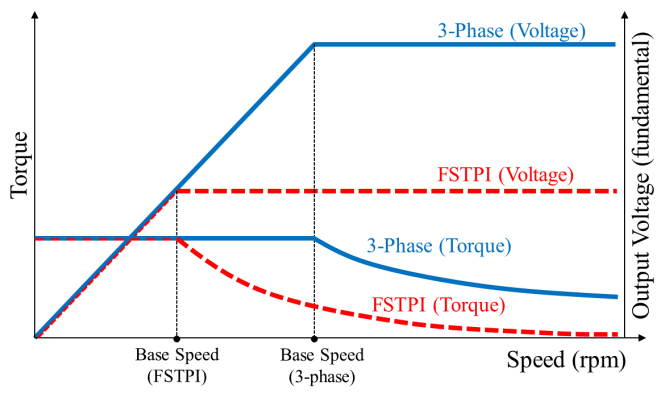

Fig. 3. Output Voltage and Base Speed

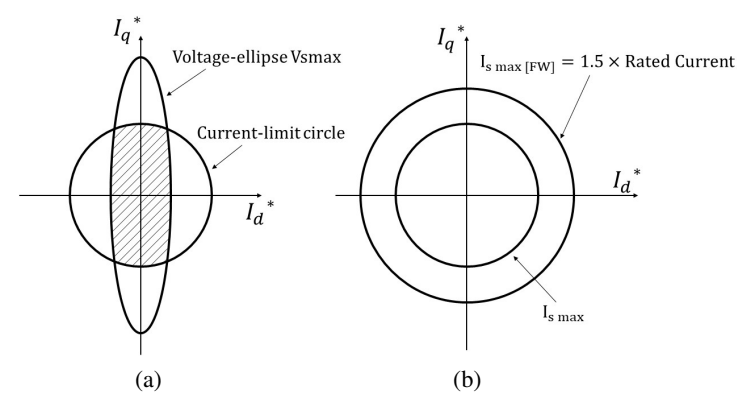

Fig. 4. Current and Voltage Limitation 


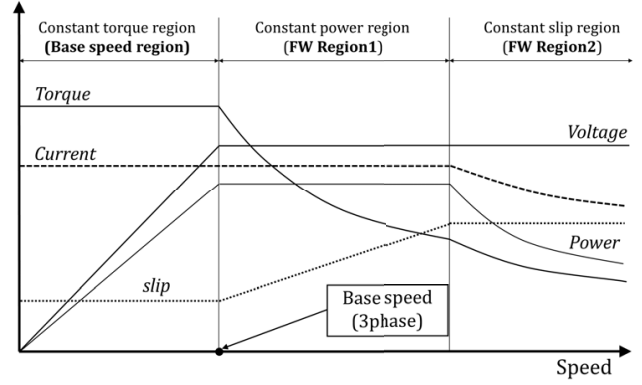

Fig. 5. Field-Weakening Characteristics of an Induction motor fed by 3-phase Inverter

$\mathrm{I}_{\text {rated }}$ of the induction motor ${ }^{(20)(21)}$.

The current ratings are confirmed and is set at $150 \%$ of its rated value. Therefore, the maximum current for the fieldweakening region $I_{s \max [F W]}$ can be expressed as shown in equation (5).

$$
I_{\text {smax }[F W]}=I_{\text {rated }} \times 1.5 \cdots
$$

3.2 Field-Weakening (FW) Characteristics of an Induction Motor Drive The characteristics of the conventional field-weakening control of an induction motor fed by a 3-phase inverter is shown in Fig. 5. In the 3-phase inverter drive, the operating range of the induction motor and its characteristics can be divided into 3 different regions. Constant torque region (Base speed region), constant power region (FW region 1) and constant slip region (FW region 2).

In the base speed region, the d-axis current reference $I_{d}{ }^{*}$ is constant and the motor operation is current limited. In fieldweakening region 1 , the motor speed is above its rated speed (motor) and the motor operation is limited by both the current and voltage limit because the induced voltage by electromotive force (EMF) approaches the inverter maximum voltage. In field-weakening region 2, the speed becomes so high that the current cannot exceed the maximum inverter current, then the slip reaches its maximum value. These are well known characteristics of 3-phase inverter-fed AC motor drives.

In contrast, there has been no detailed report on the fieldweakening region characteristics or current characteristics of an FSTPI-fed AC motor drive in the high speed region. Furthermore, when the FSTPI drive is applied as an emergency strategy for the 3-phase inverter drive, there is a need to understand the current characteristics in the high speed region, where the voltage has reached its maximum output or saturation.

Moreover, since the possibility that field-weakening control can be achieved in an FSTPI fed AC motor drive has not yet been investigated, there is a need to investigate or propose a method to control the current adequately in the high-speed region.

\section{Field-Weakening Strategy for FSTPI}

4.1 d-axis Reference In the conventional fieldweakening control strategy of the 3-phase inverter drive, the d-axis current reference $I_{d}{ }^{*}$ is kept constant below the base speed $\omega_{\text {base }}$ and above is reduced inversely to the motor speed $\omega_{r}$ as shown in equation (6).

$$
I_{d[F W]}^{*}=\frac{\omega_{\text {base }}}{\omega_{r}} \times I_{d}^{*}
$$

The constant d-axis current reference $I_{d}{ }^{*}$ is calculated by dividing the rated flux of the motor $\phi$ by the magnetizing inductance $L_{m}$ of the motor as shown in equation (7).

$$
I_{d}^{*}=\frac{\varphi}{L_{m}}
$$

In the high speed region, above the base speed, if the d-axis current reference is kept a constant as shown in equation (7), the induction motor cannot follow the reference value, due to voltage saturation (limitation). This will result in low performance characteristics in the high-speed region, because the current will not be adequately controlled. Thus, the need for a field-weakening control strategy.

The correct calculation of the base speed $\omega_{\text {base }}$ also determines the size or value of the d-axis current reference $I_{d}{ }^{*}{ }{ }_{F W]}$ for the field-weakening region. In addition, if the d-axis current reference is unnecessarily high, the q-axis current reference cannot be regulated. In the conventional 3-phase inverter drive, the base speed $\omega_{\text {base }}$ is usually set at or close to the rated speed $\omega_{\text {rated }}$ of the motor, where the voltage reaches its limit $V_{\text {smax }}$ or saturation.

However, as earlier explained in section 3.1 and from the working principle of the FSTPI ${ }^{(17)(18)}$, the voltage utilization factor of the FSTPI compared to the conventional 3-phase inverter reduces by approximately $50 \%$. Therefore, the base speed of the FSTPI drive will differ as shown in Fig. 3.

The reduction of the voltage utilization factor of the FSTPI drive can be explained using Kirchhoff's voltage law to derive the phase voltage, when a two phase reference voltage that has a phase difference of $60^{\circ}$ is applied to the 3-phase motor. If equation (2) is applied, the motor phase voltage will be as shown in equation (8). For comparison, the phase voltage of the 3-phase inverter-fed motor drive is shown in equation (9).

$$
\begin{aligned}
V_{u n} & =\sqrt{\frac{2}{3}} V \cos \left(\omega t-\frac{\pi}{6}\right) \\
V_{v n} & =\sqrt{\frac{2}{3}} V \cos \left(\omega t-\frac{5 \pi}{6}\right) \ldots \\
V_{w n} & =\sqrt{\frac{2}{3}} V \cos \left(\omega t+\frac{\pi}{2}\right) \\
V_{u n} & =\sqrt{2} V \cos \left(\omega t-\frac{\pi}{6}\right) \\
V_{v n} & =\sqrt{2} V \cos \left(\omega t-\frac{5 \pi}{6}\right) \ldots \\
V_{w n} & =\sqrt{2} V \cos \left(\omega t+\frac{\pi}{2}\right)
\end{aligned}
$$

These equations show that the output voltage of the FSTPI compared to the 3-phase inverter reduces by a factor of $\sqrt{3}^{(15)(29)}$

Therefore, in this paper, from this working principle of the FSTPI, the base speed is recalculated by dividing the rated speed $\omega_{\text {rated }}$ of the induction motor by a factor of $\sqrt{3}$ as shown in equation (10).

$$
\omega_{\text {base }[F S T P I]}=\frac{\omega_{\text {rated }}}{\sqrt{3}} .
$$

From the calculations in equation (6), (7) and (10), the daxis current reference $I_{d[F W]}^{*}$ for the high-speed region of the 
FSTPI drive can be derived as shown in equation (11).

$$
I_{d[F W]}^{*}=\frac{\omega_{\text {base }[F S T P I]}}{\omega_{r}} \times I_{d}^{*}
$$

4.2 q-axis Reference The q-axis current reference $I_{q}{ }^{*}$ in the conventional field-weakening control of the 3-phase inverter drive is controlled by limitation in various operating regions. These different limitations are not directly applicable to the FSTPI drive because its base speed and maximum output voltage reduces as shown in Fig. 3 .

In this paper, in the base speed region (constant torque region) of the FSTPI drive, the q-axis current reference $I_{q}{ }^{*}$ is limited as shown in equation (12). In this region, the maximum current $I_{\text {smax }[F W]}$ is set as given by equation (5).

$$
I_{q}^{*}=\sqrt{I_{\operatorname{smax}[F W]^{2}-I_{d}^{* 2}}}
$$

Up to the base speed of the FSTPI in equation (10), the $\mathrm{d}$-axis current reference $I_{d}{ }^{*}$ is a constant, hence, torque is proportional to the q-axis current.

Above this base speed of the FSTPI, where the fieldweakening control begins, up to the rated speed of the motor $\omega_{\text {rated }}$, the q-axis current reference is limited by the constraints in equation (13). The only difference between base speed region and this region is, the d-axis current reference is no longer constant because its value is determined by the field-weakening controller in equation (11). This region is called field-weakening region 1 (FW1) in the FSTPI drive, as shown in Fig. 6.

$$
I_{q}^{*}=\sqrt{I_{\text {smax }[F W]^{2}-I_{d[F W]}^{*}}} .
$$

In the conventional 3-phase inverter drive, in fieldweakening region 2 , the q-axis current reference is reduced by limitation, in order to keep the maximum slip as shown in equation (14) and equation (15), to avoid a loss of current control and the drive system ${ }^{(21)(30)}$.

$$
\begin{aligned}
& \omega_{\text {smax }}=\frac{I_{q}{ }^{*}}{t_{r} I_{d}{ }^{*}}=\frac{1}{t_{r} \sigma} \ldots \ldots \ldots \ldots \ldots \ldots \ldots \ldots \ldots \ldots \ldots \\
& I_{q[\max ]}^{*}=\frac{I_{d[F W]}^{*}}{\sigma}
\end{aligned}
$$

In the FSTPI drive because voltage that can be utilized in the field-weakening region is low, if equation (14) and (15) are applied, it will have no positive effect on the output torque or motor efficiency. This is because the q-axis current reference will not be as large as that of the 3-phase inverter

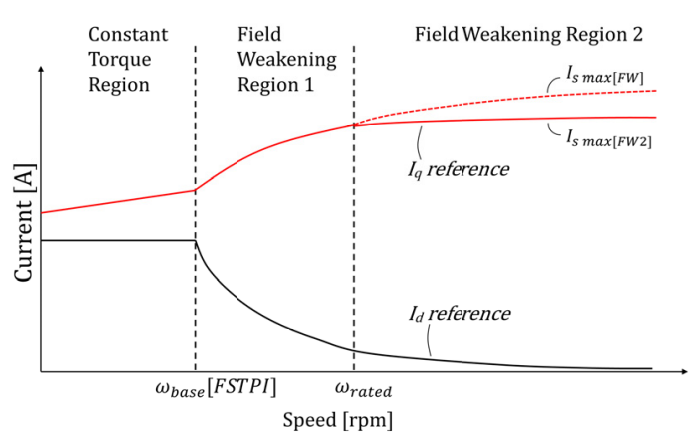

Fig. 6. Waveform of $I_{d}, I_{q}$ reference control drive. However, the q-axis current reference for the FSTPI drive will still be unnecessarily large, which will result in an unbalance in the drive, loss of torque and slip linearity, low motor efficiency and eventually the motor will stall.

Hence, in this paper, above the rated speed of the motor, a q-axis current limitation for the FSTPI drive is proposed and this region is called field-weakening region 2 .

The proposed limitation is to reduce the maximum current $I_{s \max [\mathrm{FW}]}$ that the inverter can apply to the motor, which results in a limitation of the q-axis current reference. The maximum current $I_{s \max \left[F W_{2}\right]}$ for the field-weakening region 2 is set at the rated current $I_{\text {rated }}$ of the induction motor as shown in equation (16).

$$
I_{\text {smax }[F W 2]}=I_{\text {rated }}
$$

Therefore, the q-axis current reference limitation for the field-weakening region 2 is given by equation (17).

$$
I_{q}^{*}=\sqrt{I_{\text {smax }[F W 2]^{2}-I_{d[F W]}^{*}}} .
$$

The onset of field-weakening region 2 is determined by the speed of the motor. Above the rated speed of the induction motor $\left(\omega_{\text {rated }}\right)$, field-weakening region 2 begins. This will enable the drive to attain high motor efficiency, linear relationship of torque and slip and stability in the high-speed region. The switching of limitations from field-weakening region 1 to field-weakening region 2 will be conducted using a comparator which has an input of rated speed and feedback speed of the motor.

Therefore, in the FSTPI drive, in order to attain maximum performance characteristics in the high-speed region, the qaxis current reference limitation in field-weakening regions 1 and 2 are different as shown in Fig. 6.

\section{Simulation Results}

To verify the proposed field-weakening control strategy, a simulation model is designed and implemented using PSIM software. The circuit for simulation is shown in Fig. 7. The specification of the induction motor used in the simulation is shown in Table 1. The inverter switches are considered to be ideal switches. The switching frequency is set at $10 \mathrm{kHz}$. The $\mathrm{V}$ phase of the motor is connected to the center potential of the DC source. The maximum torque limit is set at $1.49 \mathrm{Nm}$. In this simulation, in order to reduce the effect of the capacitor voltage fluctuation, due to the connection of one phase of the motor to its neutral point, a capacitor with a large capacitance of $8200 \mu \mathrm{F}$ is used ${ }^{(18)(31)}$.

For the purpose of comparison, the same experiment is carried out using a constant flux control strategy of the conventional indirect vector control as shown in Fig. 8. In the constant flux strategy, there is no field-weakening control, hence, the d-axis current reference in the whole operating speed region is the same. This comparison is important to show the characteristics of the FSTPI-fed induction motor drive without a field-weakening controller, especially in the high-speed region where the output voltage has reached its limit (saturation).

The speed reference range is set from $50 \mathrm{rpm}$ to $3000 \mathrm{rpm}$. From the simulation results, the trajectory of q-axis and daxis current and the speed-torque characteristics are evaluated. 


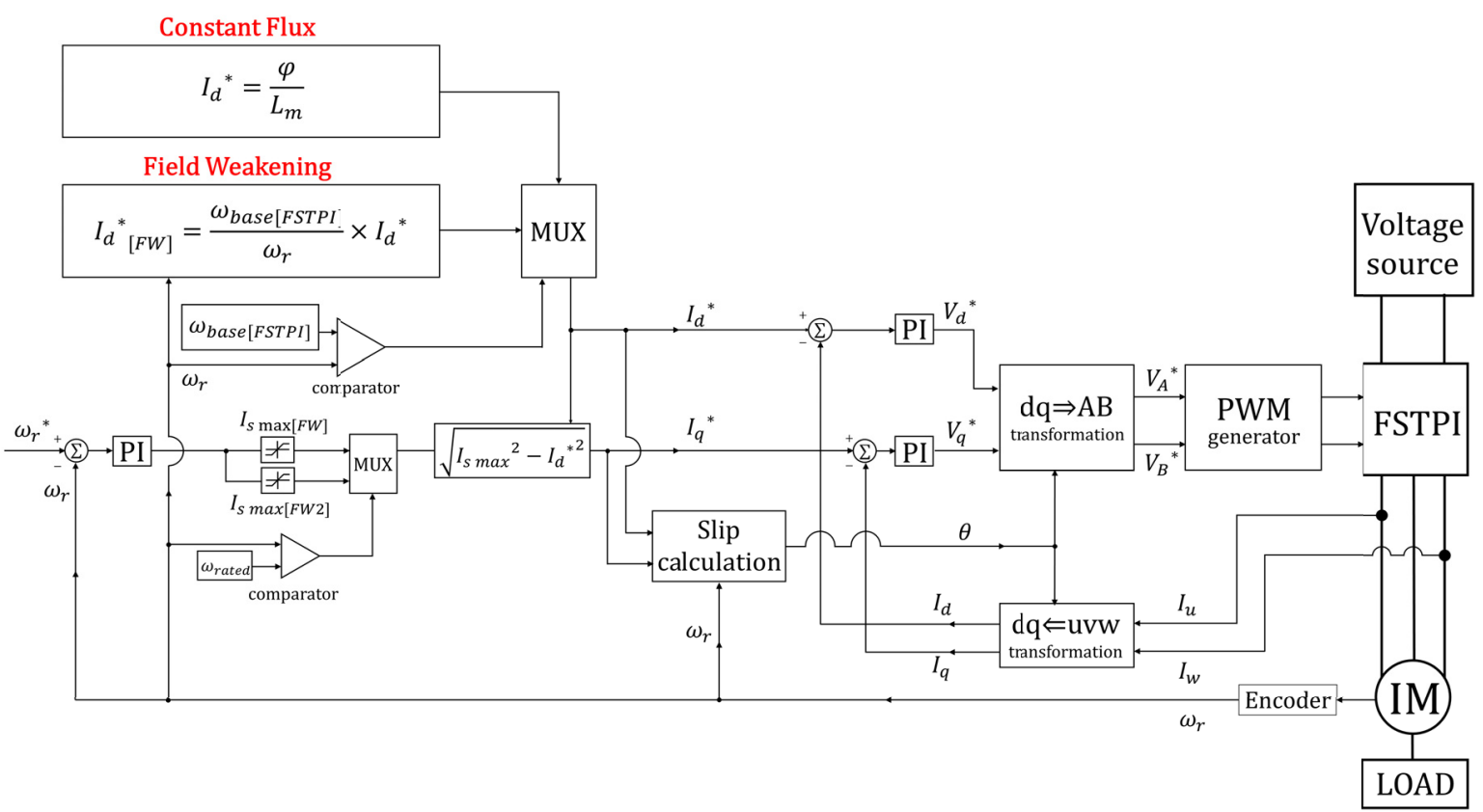

Fig. 7. Block diagram of Simulation Circuit (Field-Weakening)

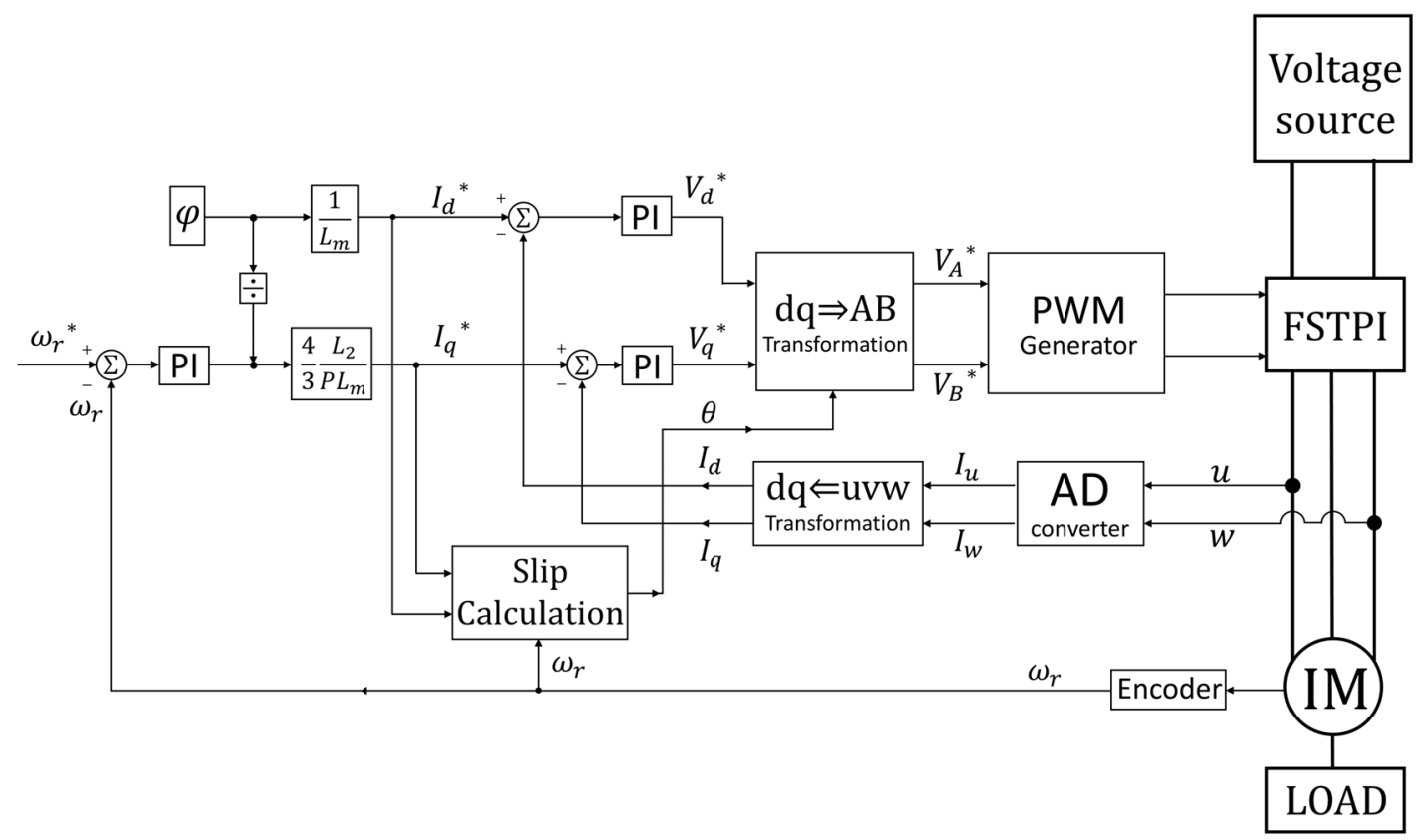

Fig. 8. Block diagram of Simulation Circuit (Constant Flux)

Table 1. Specification of Induction Motor

\begin{tabular}{|l|c|c|}
\hline \multicolumn{1}{|c|}{ Quantity } & Symbol & Value \\
\hline Rated Speed & $\mathrm{N}$ & $1250 \mathrm{rpm}$ \\
\hline Rated Torque & $\mathrm{T}$ & $1.49 \mathrm{Nm}$ \\
\hline Rated Power & $\mathrm{P}$ & $200 \mathrm{~W}$ \\
\hline Rated Voltage & $\mathrm{V}$ & $200 \mathrm{~V}$ \\
\hline Rated Current & $\mathrm{I}$ & $1.1 \mathrm{~A}$ \\
\hline Rated Frequency & $f$ & $50 \mathrm{~Hz}$ \\
\hline No. of poles & $\mathrm{P}$ & $4 \mathrm{poles}$ \\
\hline
\end{tabular}

5.1 $I_{d}$ and $I_{q}$ Trajectory Versus Speed The d-axis current and q-axis current trajectory using the proposed fieldweakening control strategy is evaluated. The speed reference is set at $2500 \mathrm{rpm}$ and the results are shown in Fig 9. For comparison, the q- axis current without field-weakening control is also shown in Fig. 9. Results show the d-axis current is constant up to the base speed and reduces in the field-weakening regions. Furthermore, the q-axis current increases up to the field-weakening region 1 and is limited in field-weakening region 2 . These results show that the q-axis and d-axis current trajectory follows the proposed field-weakening control strategy.

5.2 Speed-Torque Characteristics The maximum attainable torque of both the constant flux control and the proposed field-weakening control are shown in Fig. 10. A comparison of the results show that above the base speed (rpm), compared to the constant flux control, the proposed field-weakening control strategy can produce more torque by 


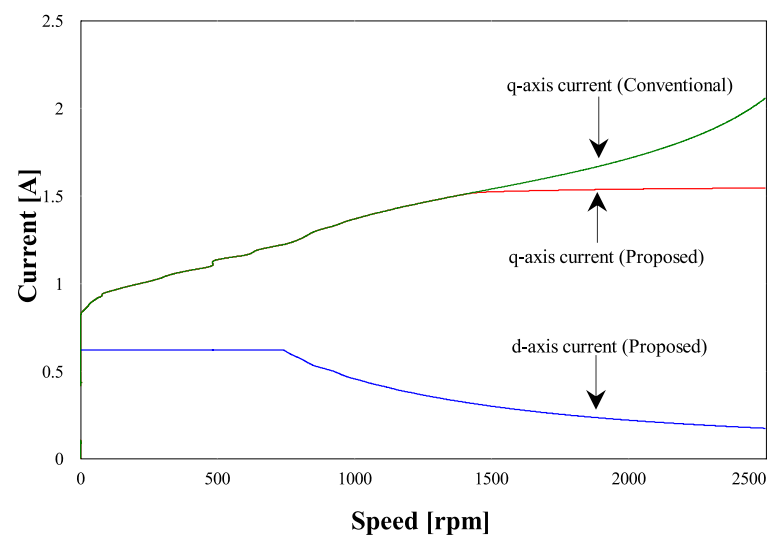

Fig. 9. $I_{d}$ and $I_{q}$ Trajectory Vs speed (Simulation)

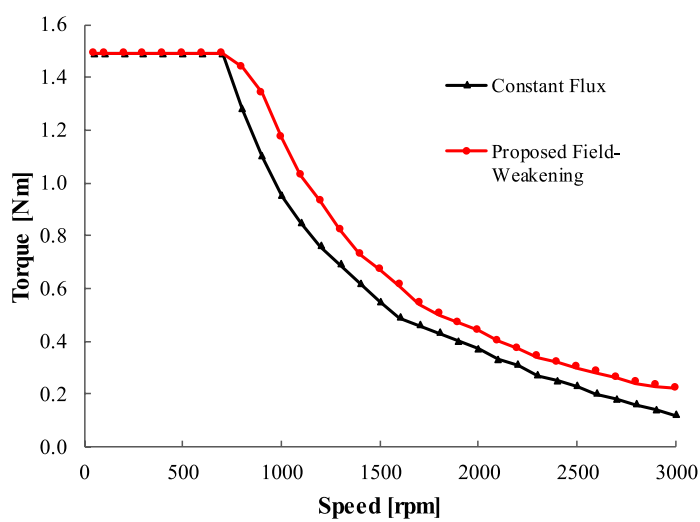

Fig. 10. Torque vs Speed (Simulation)

approximately $12 \%$ at the maximum and $8 \%$ on the average.

\section{Experimental System}

An experiment is carried out to verify the simulation results. In the experiment, a $10 \mathrm{kHz}$ IGBT Four-Switch ThreePhase Inverter-fed 3-phase induction motor drive system is used. The experiment system configuration is shown in Fig. 11. The V phase of the motor is connected to the center potential of the DC source. A capacitor with a large capacitance of $8200 \mu \mathrm{F}$ is used to reduce the capacitor voltage fluctuation, due to one phase of the motor connected to its neutral point.

A Digital Signal Processor (DSP) is used to implement the control algorithm in software (PE-VIEW9). An incremental encoder is mounted on the shaft for detecting the rotor position which is feed to the motor controller via the DSP. A DC generator (DCG) is used as the load for the experiment.

The torque is measured using a high accuracy torque sensor, which is mounted as a mechanical coupler between the induction motor shaft and the load (DCG). The inverter DClink voltage is $283 \mathrm{~V}$. The specification of the induction motor is shown in Table 1. The same experiment is carried out using both constant flux control and proposed field-weakening control strategy.

\section{Experimental Results}

The experimental results of the speed-torque characteristics and motor efficiency of the entire operating region are evaluated. A motor efficiency map is plotted to evaluate the performance of the drive.

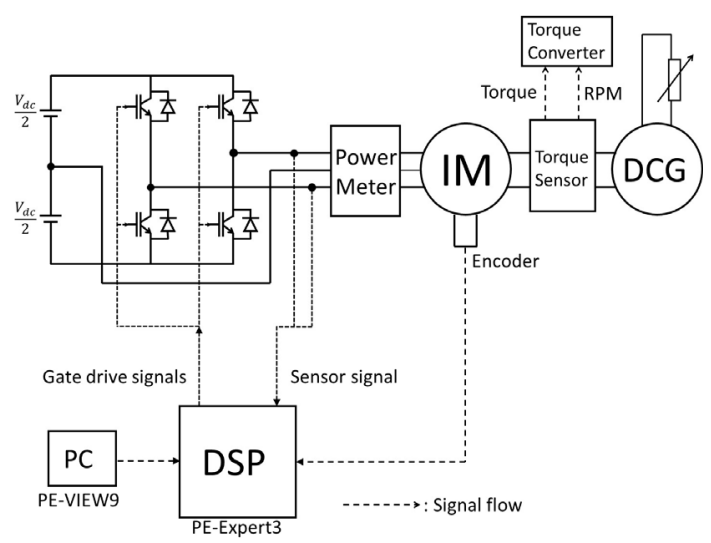

Fig. 11. Experiment system configuration

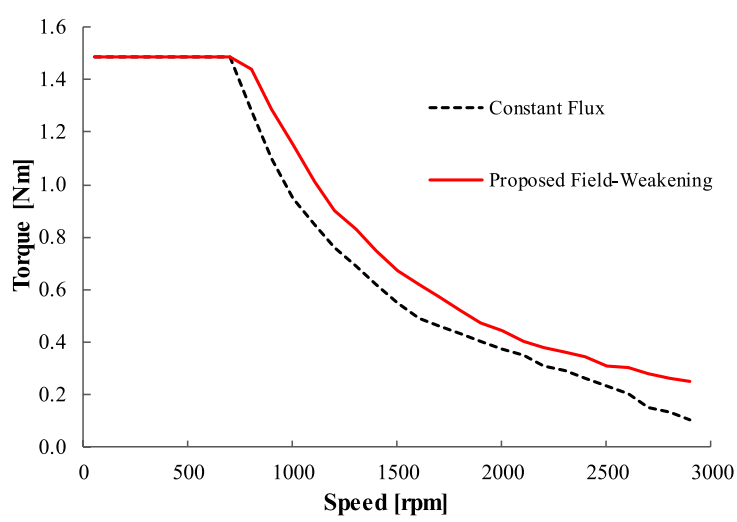

Fig. 12. Torque-Speed Characteristics (Experiment)

7.1 Speed-Torque Characteristics The speed reference was changed from $50 \mathrm{rpm}$ to $3000 \mathrm{rpm}$. At each speed, the maximum torque limit was set at $1.49 \mathrm{Nm}$ (rated torque). The speed was increased by $50 \mathrm{rpm}$ from its minimum value $(50 \mathrm{rpm})$ to its maximum value $(3000 \mathrm{rpm})$ and the maximum attainable torque was recorded. The speed-torque characteristics using both the constant flux and the proposed fieldweakening control strategies are shown in Fig. 12.

The results show that from the low-speed region to approximately $700 \mathrm{rpm}$, the maximum attainable torque of both strategies are the same. Above $700 \mathrm{rpm}$, the proposed fieldweakening control can produce a higher maximum torque compared to the constant flux control strategy by an average of $6 \%$ per speed.

A comparison of the simulation and experimental results shows a slight reduction in the maximum attainable torque of both control strategies. However, the improvement by applying the proposed strategy can be seen.

7.2 Motor Efficiency The efficiency of the induction motor driven by the FSTPI is examined by plotting a motor efficiency map. A 2D plot of the motor efficiency and torque versus its rotation speed enables easy evaluation of low and high efficiency speed regions.

In the experiment, the maximum torque limit was set at $1.49 \mathrm{Nm}$, which is the rated torque of the induction motor used in the experiment. The speed range was set from $50 \mathrm{rpm}$ to $3000 \mathrm{rpm}$. At each speed, the torque was increased by steps of $0.1 \mathrm{Nm}$ from $0.1 \mathrm{Nm}$ to the maximum attainable torque, in order to increase the data points and enable evaluation accuracy. 


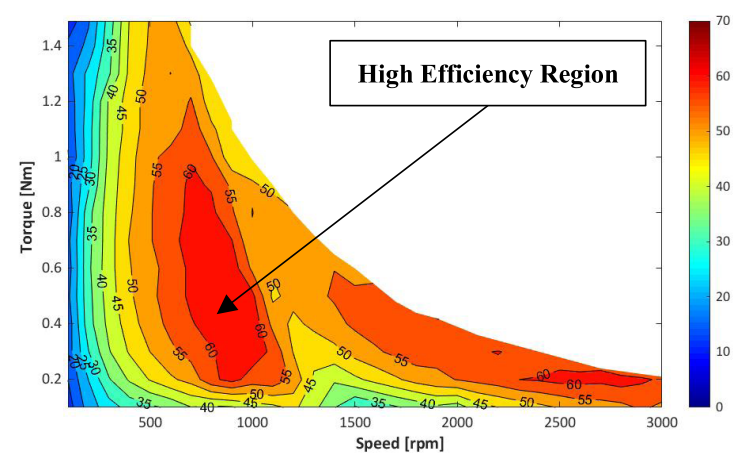

Fig. 13. Motor Efficiency Map (Constant Flux)

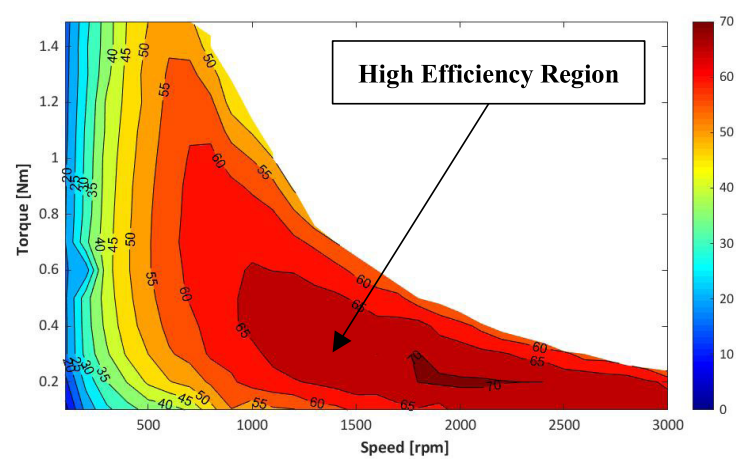

Fig. 14. Motor Efficiency Map (Proposed Field-Weakening)

The results of the constant flux control and the proposed field-weakening control strategy are shown in Fig. 13 and Fig. 14 respectively. The constant flux control results show that the maximum efficiency region is between $55 \%$ and $60 \%$ from $650 \mathrm{rpm}$ to $750 \mathrm{rpm}$. The results in Fig. 14 show the maximum motor efficiency region using the proposed fieldweakening strategy is between $60 \%$ and $65 \%$ from $700 \mathrm{rpm}$ to $3000 \mathrm{rpm}$.

A comparison of the two results show that the proposed field-weakening control strategy can achieve a higher efficiency over a wider speed range.

\section{Conclusion}

In this paper, a new and simple field-weakening control strategy for Four-Switch Three-Phase Inverter-fed induction motor drive is proposed to optimize the speed-torque characteristics and motor efficiency in the high-speed region.

The feasibility of the proposed control strategy is verified by simulation results and validated by the experimental results. Results show by applying the proposed fieldweakening control, the maximum attainable torque and motor efficiency increased in the high-speed region.

This paper is the first report that has proposed and successfully achieved a field-weakening control for an FSTPIfed motor drive. Furthermore, the results in this paper shows that field-weakening control can also be achieved in FSTPIfed induction motor drive and other AC motor drives, when applied as an emergency strategy for the standard 3-phase inverter-fed AC motor drive.

\section{References}

( 1 ) K. Halder, J. Islam, and A. Rafiq: "Vector control of a cost effective FSTP inverter fed synchronous reluctance motor drive based on recurrent neural network", The Pacific Journal of Science and Technology, Vol.12, No.12, pp.20-26 (2011)

( 2 ) M.N. Uddin, T.S. Radwan, and M.A. Rahman: "Fuzzy-logic-controller based cost-effective four-switch three-phase inverter-fed IPM synchronous motor drive system", IEEE Trans. Industry Appl., Vol.42, No.1, pp.21-30 (2006)

( 3 ) S. Ekmen, B. Fincan, and M. Imeryuz: "A BLDC motor drive with four switch three phase inverter", Proc. Int. Conf. on Renewable Energy Research and Applications, pp.804-808 (2016)

( 4 ) D. Kumar, R. Gupta, and N. Gupta: "Minimization of current ripple and overshoot in four switch three-phase inverter fed BLDC motor using tracking anti-windup PI controller", Proc. Int. Conf. on Signal Processing, Informatics, Comm. and Energy Systems, pp.1-6 (2017)

( 5 ) C. Zhu, Z. Zeng, and R. Zhao: "Comprehensive analysis and reduction of torque ripples in three-phase four-switch inverter fed PMSM drives using space vector pulse-width modulation", IEEE Trans. Power Electronics, Vol.32, No.7, pp.5411-5424 (2017)

( 6 ) H.H. Lee, P.Q. Dzung, L.D. Khoa, and L.M. Phuong: "Dynamic adaptive space vector PWM for four switch three phase inverter fed induction motor with compensation of DC-link voltage ripple", Proc. IEEE Int. Conf. on Power Electron and Drive systems, pp.399-404 (2009)

( 7 ) F. Blaabjerg, S. Freysson, H.H. Hansen, and S. Hansen: "A new optimized space-vector modulation strategy for a component-minimized voltage source inverter", IEEE Trans. Power Electronics, Vol.12, No.4, pp.704-714 (1997)

( 8 ) Q.T. An, L. Sun, K. Zhao, and T.M. Jahns: "Scalar PWM algorithms for fourswitch three-phase inverters", IET Electronic Letters, Vol.14, No.13, pp.900902 (2010)

( 9 ) Z. Zeng, C. Zhu, X. Jin, W. Shi, and R. Zhao: "Hybrid Space Vector Modulation Strategy for Torque Ripple Minimization in Three-Phase Four- Switch Inverter-Fed PMSM Drives", IEEE Trans. Ind. Electronics, Vol.64, No.3, pp.2122-2134 (2017)

(10) J. Kim, J. Hong, and K. Nam: "A current distortion compensation scheme for four-switch inverter", IEEE Trans. Power Electronics, Vol.24, No.4, pp.1032-1040 (2009)

(11) K. Matsuse, N. Kezuka, and K. Oka: "Characteristics of independent two induction motor drives fed by a four-leg inverter", IEEE Trans. Industry Appl., Vol.47, No.5, pp.2125-2134 (2011)

(12) R. Wang, J. Zhao, and Y. Liu: "A comprehensive investigation of four-switch three phase voltage source inverter based on double fourier integral analysis", IEEE Trans. Power Electronics, Vol.26, No.10, pp.2774-2787 (2011)

(13) S. Kazemlou and M.R. Zolghadri: "Direct torque control of four switch three phase fed induction motor using a modified SVM to compensate DC-Link voltage imbalance", Proc. Int. Conf. on Power and Energy Conversion Systems, pp.1-6 (2009)

(14) G.A. Covic and G.L. Peters: "DC link imbalance compensation in fourswitch inverter AC motor drives", IET Electronic Letters, Vol.33, No.13, pp.1101-1102 (1997)

(15) H.W.V.D. Broeck and J.D.V. Wyk: "A comparative investigation of a threephase induction machine drive with a component minimized voltage-fed inverter under different control options", IEEE Trans. Industry Appl., Vol.IA20, No.2, pp.309-320 (1984)

(16) U.U. Ekong, M. Inamori, and M. Morimoto: "Field oriented control of two phase inverter to drive a three phase induction motor", Proc. Int. Conf. on Electrical. Machines and Systems, pp.125-128 (2015)

(17) U.U. Ekong, M. Inamori, and M. Morimoto: "Instantaneous vector control of four switch three phase inverter fed induction motor drive", Proc. Int. Conf. on Electrical. Machines and Systems, pp.1-6 (2016)

(18) U.U. Ekong, M. Inamori, and M. Morimoto: "Instantaneous vector control of four switch three phase inverter fed induction motor drive", IEE Japan Trans. Industry Appl., Vol.6, No.6, pp.429-434 (2017)

(19) O. Sok, U.U. Ekong, M. Inamori, and M. Morimoto: "Evaluation of motor efficiency of a vector controlled 2 phase inverter fed 3 phase induction motor drive", IEE Japan Industry Appl. Society Annual Conf., pp.369-372 (2017)

(20) X. Xu and D.W. Novotny: "Selection of the flux reference for induction machine drives in the field weakening region", IEEE Trans. Industry Appl., Vol.28, No.6, pp.1353-1358 (1992)

(21) S. Kim and S. Sul: "Maximum torque control of an induction machine in the field weakening region", IEEE Trans. Industry Appl., Vol.31, No.4, pp.787794 (1995)

(22) M.H. Shin, D.S. Hyun, and S. Cho: "Maximum torque control of stator-flux oriented induction machine drive in the field-weakening region", IEEE Trans. Industry Appl., Vol.38, No.1, pp.117-122 (2002)

(23) S. Kim and S. Sul: "Voltage control strategy for maximum torque operation of an induction machine in the field weakening region", IEEE Trans. Ind. Electronics, Vol.44, No.4, pp.512-518 (1997)

(24) L. Harnefors, K. Pietilainen, and L. Gertmar: "Torque-maximizing field 
weakening control: design, analysis, and parameter selection", IEEE Trans. Ind. Electronics, Vol.48, No.1, pp.161-168 (2001)

(25) H. Grotstollen and J. Wiesing: "Torque capability and control of a saturated induction motor over a wide range of flux weakening”, IEEE Trans. Ind. Electronics, Vol.42, No.4, pp.374-381 (1995)

(26) M. Megoni, L. Zarri, A. Tani, G. Serra, and D. Casadei: "A comparison of four robust control schemes for field-weakening operation of induction motors", IEEE Trans. Power Electronics, Vol.27, No.1, pp.307-320 (2012)

(27) U.U. Ekong, M. Inamori, and M. Morimoto: "Improved torque and efficiency of a four switch three phase inverter fed induction motor drive", IEEE Int. Conf. on Power Elect. and Drives Systems, pp.919-924 (2017)

(28) F. Yusivar, T. Kihara, M. Sato, S. Wakao, and T. Yamamura: “/Iq/ Added flux weakening strategy for the rotor flux oriented control of a sinusoidal PWM VSI-fed induction motor", IEEE Ind. Electronics Society, $27^{\text {th }}$ Annual Conf., pp.1160-372 (2001)

(29) G.A. Covic, G.L. Peters, and J.T. Boys: "An improved single phase to three phase converter for low cost AC motor drives", Proceeding of Int. Conf. on Power Elec. And Drive Systems (PEDS), Vol.1, pp.549-554 (1995)

(30) D.W. Novotny and T.A. Lipo: Vector control and dynamics of ACdrives, Oxford: pp.41-3 (1996)

(31) H. Tanaka, S. Saito, and K. Matsuse: "Capacitor voltage balancing control of four-leg inverter for two vector controlled induction motor drives", IEE Japan Trans. Industry Appl., Vol.3, No.4, pp.310-317 (2014)

Ufot Ufot Ekong (Member) was born in Lagos, Nigeria, in 1990. He

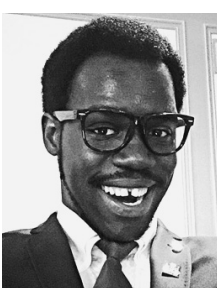

received his B.Sc. and M.Sc. degree in electrical and electronics engineering from Tokai University Japan in 2014 and 2016. Presently, He is pursuing a Ph.D. degree at Tokai University. His research interests include power electronics and its applications, fault tolerant control and ac machines drives. He is a member of IEEE-IAS and IEEJ-IAS.
Mamiko Inamori (Member) was born in Kagoshima, Japan in 1982.

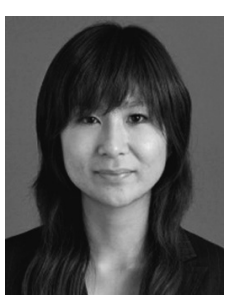
She received her B.Sc., M.Sc. and Ph.D. degree in electronics engineering from Keio University, Japan in 2005, 2007 and 2009 respectively. In 2009, she joined Keio University where she was a lecturer. In 2013, she joined the Faculty of Engineering, Tokai University as a lecturer. Presently, she is an Associate Professor at the Department of Electrical and Electronics Engineering. She received the Young Scientist Award from Ericsson Japan in 2010. Her research interests are mainly concentrated on power and communication systems.

Masayuki Morimoto (Fellow) was born in Tokyo, Japan in 1952. He

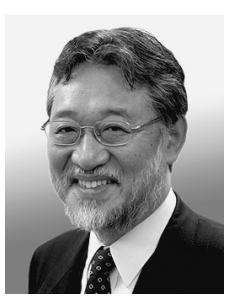
received his B.Sc., M.Sc. and Ph.D. degree in electrical engineering from Keio University, Japan in 1975, 1977 and 1990 respectively. He worked at Mitsubishi Heavy Industries, Ltd. from 1977 to 2005. From 2005 to 2018, He was a Professor at the Department of electrical and electronics engineering, Tokai University. Presently, $\mathrm{He}$ is a lecturer at the same university. His research interests are in the areas of power electronics and its applications, electric machines and drives, and vehicle application. He is the Author of more than 10 books. 